\title{
Mechanism of Glomerulotubular Balance. II. Regulation of Proximal Tubular Reabsorption by Tubular Volume, as Studied by Stopped-Flow Microperfusion *
}

\author{
Felix P. Brunner, $†$ Floyd C. Rector, JR. $\$$ and Donald W. Seldin with the \\ technical assistance of Allen C. NunN \\ (From the Department of Internal Medicine, The University of Texas Southwestern \\ Medical School, Dallas, Texas)
}

Recent micropuncture studies (1-3) have shown that reductions in glomerular filtration rate (GFR) induced by aortic constriction are accompanied by proportionate changes in the rate of proximal tubular reabsorption, thus maintaining constant fractional reabsorption (i.e., glomerulotubular balance). We have shown, however, that similar reductions in GFR, induced by elevating ureteral pressure, are associated with increased fractional reabsorption in the proximal convoluted tubule (3). An analysis of the effects of aortic constriction and increased ureteral pressure on the relations among GFR, fractional reabsorption, tubular velocity, and tubular size led to the conclusion that tubular volume was the critical factor governing the proximal reabsorptive rate (3).

In our previous studies, however, tubular volume and reabsorptive rate were estimated indirectly from an analysis of tubular fluid to plasma ratios of inulin $\left[(\mathrm{TF} / \mathrm{P})_{\mathrm{In}}\right]$ and the transit time. The present experiments were designed to investigate in a more direct fashion the effects of altering tubular dimensions on the intrinsic reabsorptive capacity of the tubular epithelium. The stoppedflow microperfusion technique of Gertz (4), in which the rate of reabsorption of a drop of isotonic saline placed between two columns of oil in an isolated segment of the tubule is measured, was used

* Submitted for publication August 25, 1965 ; accepted December 27, 1965.

This work was supported in part by a grant from the Dallas Heart Association and in part by training grant 5 TI HE 5469-04 from the National Institutes of Health, U. S. Public Health Service.

† Work performed as a trainee of the U. S. Public Health Service, grant 5 TI HE 5469-04.

$\ddagger$ Address requests for reprints to Dr. Floyd C. Rector, Jr., Dept. of Internal Medicine, The University of Texas Southwestern Medical School, 5323 Harry Hines Blvd., Dallas, Texas 75235. to estimate the intrinsic reabsorptive capacity of the tubular epithelium. This method has the great advantage of permitting an assessment of tubular reabsorption independent of glomerular filtration and velocity flow.

In the first series of experiments the effect of renal hypoperfusion, induced by constriction of the aorta above the renal arteries, on the rate of proximal reabsorption was examined. In the second series of experiments the role of tubular geometry in glomerulotubular balance was evaluated more precisely by measuring the rate of tubular reabsorption before and after dilatation of the proximal tubules. Graded dilatation was achieved by applying hydrostatic pressure to the renal pelvis. In a third series of experiments, increased ureteral pressure was superimposed on aortic constriction to exclude the possibility that the experimental procedure per se rather than tubular size was determining reabsorption.

\section{Methods}

Unilaterally nephrectomized Sprague-Dawley rats were prepared for micropuncture studies as described in the preceding paper (3). Glomerular filtration rate (GFR) was measured with inulin $-{ }^{14} \mathrm{C}$. Transit times through the visible portions of the proximal tubules were measured according to the method of Steinhausen (5).

Proximal tubular reabsorptive rate was determined by the technique of Gertz (4). A proximal convolution on the surface of the kidney was punctured through the intact capsule with a double-barreled micropipette, one barrel filled with castor oil stained by Sudan black, the other barrel filled with $0.15 \mathrm{M} \mathrm{NaCl}$. The tubule was first filled with castor oil. The column of oil was then split by injecting saline from the other barrel. After this, more oil was injected into the tubule to move the saline column away from the pipette into an intact segment of tubule. The rate at which the saline drop was reabsorbed was determined by photographing the surface of the kidney at 6-second intervals with a Nikon camera 

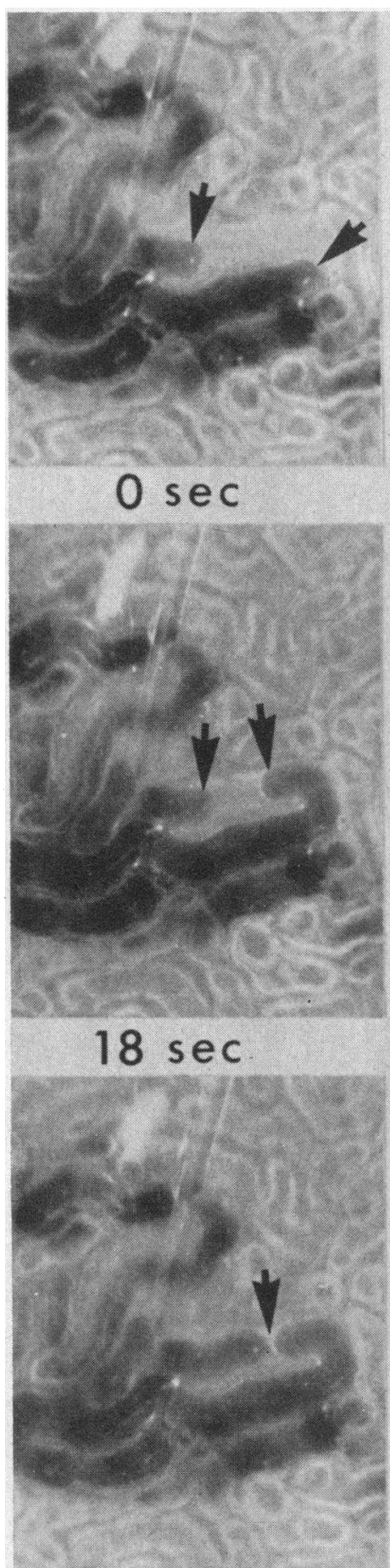

$36 \mathrm{sec}$

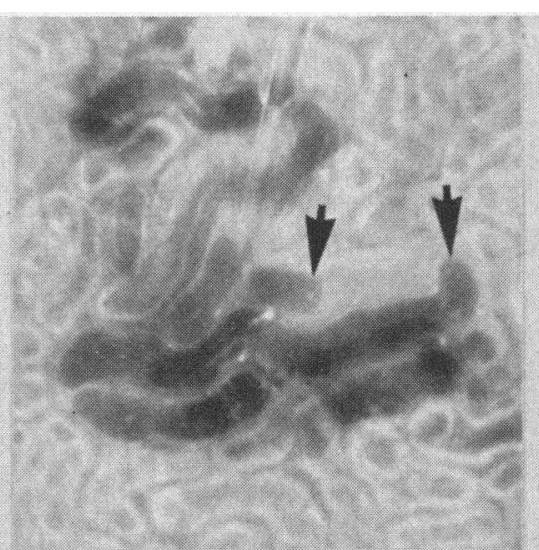

$6 \mathrm{sec}$

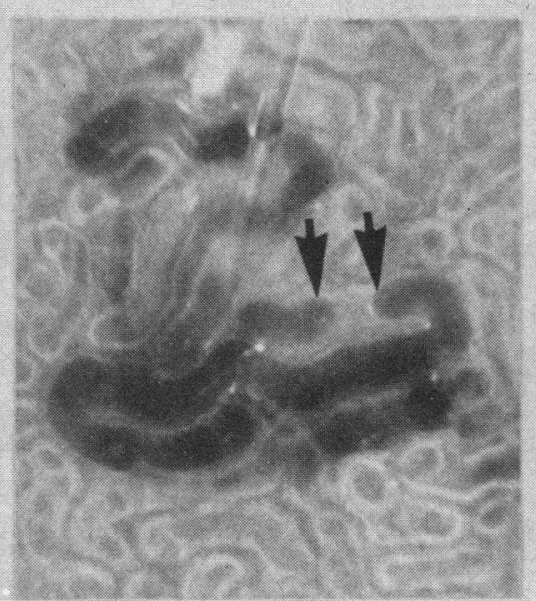

$24 \mathrm{sec}$

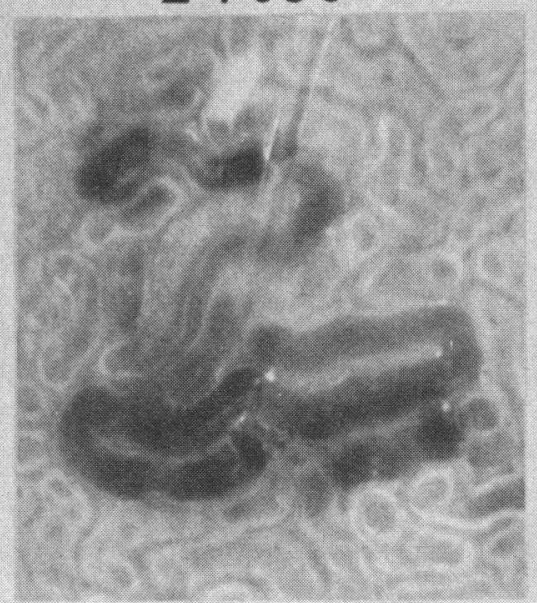

$42 \mathrm{sec}$

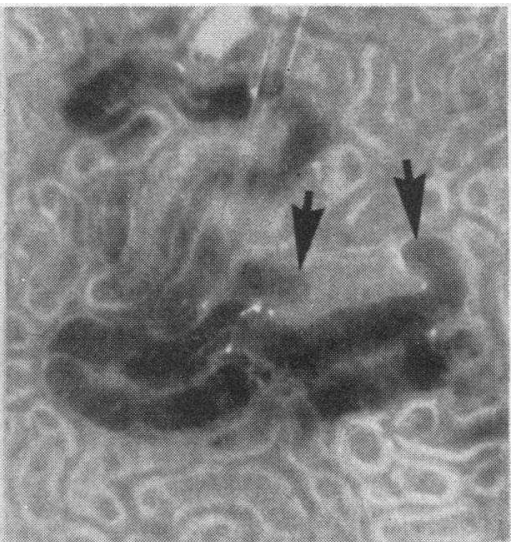

12 'sec

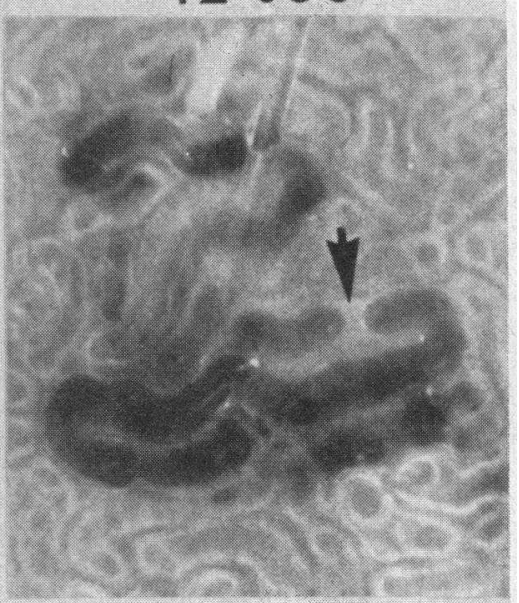

$30 \mathrm{sec}$

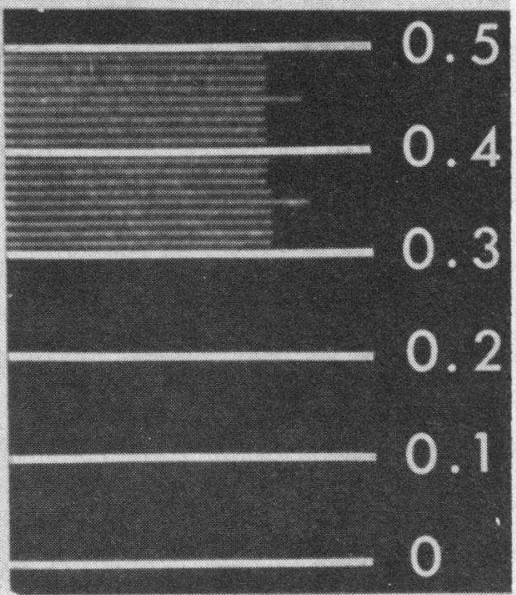

$\mathrm{m} m$

Fig. 1. Timed-sequence photographs of a DRop of SAline instilled into the proximal tubule. The dark loops are filled with castor oil stained with Sudan black. The menisci of the saline drop are indicated by the arrows. A calibrated scale photographed at the same magnification as the kidney is shown in the lower right corner. 
with automatic film advance. The camera was mounted on a Leitz Ultrapak microscope with a divided light beam. An electronic control unit ${ }^{1}$ synchronized the camera shutter, the electronic flash, and the film advance, controlled the time interval between photographs, and furnished power for charging the flash lamp. The light intensity of the flash unit was $200 \mathrm{w}$-seconds. In each of the sequential photographs the length of the saline column and the luminal radius were measured.

In the first series of experiments reabsorptive rate and transit time were determined before and after reducing renal blood flow by aortic constriction. In a second series of experiments (seven rats) the effects of increased ureteropelvic pressure were examined. In a third series of experiments (two rats) the effects of superimposing increased ureteral pressure on aortic constriction were investigated. Constriction of the aorta and elevation of ureteral pressure were performed exactly as described in the preceding paper (3).

\section{Results}

Control studies. A good example of the measurement of tubular reabsorption by timed-sequence photography is shown in Figure 1. It should be noted that the diameter of the injected tubule appears to be larger than the surrounding tubules. This is in part due to underestimation of the size of the uninjected tubules because the overlying

1 The electronic flash and control unit was built in the Dept. of Biomedical Engineering at The University of Texas Southwestern Medical School. capillaries obscure the luminal borders. However, there appears to be some tubular dilatation induced by injection of the castor oil. In all experiments we noted that tubular radius remained relatively constant during the period of measurement. The mean radius during control measurements was $16.8 \pm 1.1 \mu( \pm \mathrm{SD})$

Since the reabsorptive area decreases as the saline drop shrinks, the absolute rate also decreases as a function of time. By plotting the logarithm of the length of the saline column against time a straight line is obtained; the reabsorptive halftime $\left(t_{1}\right)$ and reabsorptive rate constant $(C)$ can be calculated from the slope of the line. The mean $t_{i}$ of $10.2 \pm 1.4$ seconds was estimated from 103 measurements from the two control groups of Table I and the control group of Table II. These $t_{1}$ times are very similar to those obtained by Gertz (4) and by Giebisch and associates (6) We found, in confirmation of Gertz, that the $t_{1}$ was remarkably constant from animal to animal and from tubule to tubule, and was independent of tubular location.

The reabsorptive rate $(\mathrm{C})$ can be calculated from the reabsorptive $t_{1}$ and the tubular radius ( $r$ ) by the equation, $C=0.693 \pi r^{2} / t_{1}$. The average value for $\mathrm{C}$ in the control studies, therefore, was $0.6 \mathrm{~m} \mu \mathrm{l}$ per second per $\mathrm{cm}$ tubular length, as esti-

TABLE I

Effect of aortic constriction on proximal reabsorption*

\begin{tabular}{|c|c|c|c|c|c|c|c|}
\hline Procedure & $\begin{array}{l}\text { Femoral } \\
\text { blood } \\
\text { pressure }\end{array}$ & GFR† & $\begin{array}{l}\text { Tubular } \\
\text { radius }\end{array}$ & $\underset{t_{t}}{\text { Reabsorptive }}$ & $\begin{array}{l}\text { Reabsorptive } \\
\text { rate constant }\end{array}$ & $\underset{\text { time }}{\text { Transit }}$ & $\begin{array}{l}\text { Fractional } \\
\text { reabsorption } \ddagger\end{array}$ \\
\hline & $\begin{array}{l}m m \mathrm{Hg} \\
\text { Group I. }\end{array}$ & $\begin{array}{c}\mathrm{ml} / \mathrm{min} / \mathrm{kg} \\
\text { No fluid replacer }\end{array}$ & $\begin{array}{c}\mu \\
(7 \text { rats })\end{array}$ & seconds & $m \mu l / c m / s e c o n d$ & seconds & $\%$ \\
\hline Control & $110-125$ & $5.4 \pm 1.1$ & $16.6 \pm 0.5$ & $10.6 \pm 1.5$ & 0.565 & $10.2 \pm 0.7$ & 49 \\
\hline Aortic const. & $90-95$ & & $16.3 \pm 1.0$ & $11.8 \pm 2.5$ & 0.490 & $14.5 \pm 1.2$ & 57 \\
\hline Aortic const. & $80-85$ & $1.9 \pm 1.0$ & $15.9 \pm 1.2$ & $12.0 \pm 1.9(10)$ & 0.458 & $20.0 \pm 4.8$ & 68 \\
\hline Aortic const. & $70-75$ & & $13.9 \pm 1.6$ & $15.5 \pm 1.4(15)$ & 0.271 & $42.0 \pm 7.5$ & 85 \\
\hline \multirow[t]{2}{*}{ Aortic const. } & $60-65$ & & $14.0 \pm 1.1$ & $17.8 \pm 3.9(10)$ & 0.239 & Indefinite & \\
\hline & Group II. & Complete fluid & cement $(6 \mathrm{ra}$ & & & & \\
\hline Control & $115-130$ & $9.5 \pm 0.9$ & $16.5 \pm 0.7$ & $9.8 \pm 2.0(30)$ & 0.606 & $9.0 \pm 0.5$ & 47 \\
\hline Aortic const. & $70-75$ & $6.4 \pm 0.8$ & $15.2 \pm 1.2$ & $10.2 \pm 1.7$ & 0.492 & $9.2 \pm 0.6$ & 47 \\
\hline Aortic const. & $60-65$ & $4.9 \pm 1.2$ & $14.0 \pm 1.3$ & $10.5 \pm 1.9(12)$ & 0.416 & $9.0 \pm 0.5$ & 45 \\
\hline
\end{tabular}

* All values represent means \pm standard deviations. The numbers in parentheses indicate the number of measurements.

$+\mathrm{GFR}=$ glomerular filtration rate.
$\ddagger$ Calculated as follows:

$$
\text { per cent reabsorption }=\left[1-\frac{1}{\operatorname{antilog}\left(\frac{0.301 \mathrm{~T}}{t_{1}}\right)}\right] 100, \text { where } \mathrm{T}=\text { transit time. }
$$

This expression is derived from the following relationships (4):

per cent reabsorption $=\left[1-1 /(\mathrm{TF} / \mathrm{P})_{\mathrm{In}}\right] 100$,

$\log (\mathrm{TF} / \mathrm{P})_{\mathrm{In}_{n}}=\frac{0.301 \mathrm{~T}}{\mathrm{t}_{\mathbf{l}}} .(\mathrm{TF} / \mathrm{P})_{\mathrm{I}_{\mathrm{n}}}=$ tubular fluid to plasma ratio of inulin. 
TABLE II

Effect of elevated ureteral pressure on proximal reabsorption*

\begin{tabular}{cccc}
\hline $\begin{array}{c}\text { Ureteral } \\
\text { pressure }\end{array}$ & $\begin{array}{c}\text { Number } \\
\text { of meas- } \\
\text { urements }\end{array}$ & $\begin{array}{c}\text { Tubular } \\
\text { radius }\end{array}$ & $\begin{array}{c}\text { Reabsorptive } \\
t_{\frac{1}{2}}\end{array}$ \\
\hline$m m \mathrm{Hg}$ & & $\mu$ & seconds \\
0 & 47 & $16.4 \pm 1.2$ & $10.0 \pm 1.4$ \\
25 & 8 & $17.5 \pm 0.4$ & $9.1 \pm 0.6$ \\
40 & 28 & $19.8 \pm 0.8$ & $10.4 \pm 1.6$ \\
60 & 18 & $19.2 \pm 1.4$ & $14.6 \pm 3.0$ \\
\hline
\end{tabular}

* All values represent means \pm standard deviations.

mated from the pooled control data listed in Tables I and II.

Studies with aortic constriction. Table I lists the effects of aortic constriction on proximal reabsorption. Two different responses were observed, depending on pretreatment of the animals. In the first group of seven rats (group I) the fluid losses during the surgical procedure were not replaced. In the second group of six rats (group II) the surgical losses of fluid were fully replaced, but not to the extent of inducing saline diuresis (urine to plasma inulin ratios ranged from 200 to 420 ). The control arterial blood pressure (BP) in the two groups was identical, but the average GFR in group I was $5.4 \mathrm{ml}$ per minute per $\mathrm{kg}$, compared to $9.5 \mathrm{ml}$ per minute per $\mathrm{kg}$ body $\mathrm{wt}$ in the second group.

A) No fluid replacement. Lowering femoral arterial blood pressure in stepwise decrements to $80 \mathrm{~mm} \mathrm{Hg}$ in this group of rats (Table I, group I) resulted in a slight decrease in kidney size; GFR fell by $65 \%$. Further constriction resulted in marked contraction of kidney size and blanching of the kidney; many of the tubular lumina were seen to be collapsed, urine formation ceased, and GFR could not be measured.

The mean transit time, which was 10.2 seconds in the control periods (BP 110 to $125 \mathrm{~mm} \mathrm{Hg}$ ), rose progressively as pressure was lowered to 14.5 seconds at 90 to $95 \mathrm{~mm} \mathrm{Hg}, 20$ seconds at 80 to $85 \mathrm{~mm} \mathrm{Hg}$, and 42 seconds at 70 to $75 \mathrm{~mm} \mathrm{Hg}$ and was indefinitely prolonged at 60 to $65 \mathrm{~mm} \mathrm{Hg}$. At blood pressures of $80 \mathrm{~mm} \mathrm{Hg}$ or lower the flow of Lissamine green through the tubules was not uniform; the dye appeared in and disappeared from different tubules at different times; in some tubules the dye never appeared, and in others the dye appeared but did not disappear. In other words there appeared to be marked heterogeneity of nephron function at these lower pressures.
The mean reabsorptive $t_{\frac{1}{2}}$ increased only slightly as blood pressure was lowered to 80 to $85 \mathrm{~mm} \mathrm{Hg}$ (Table I). Further reductions in blood pressure, however, caused significant prolongation of the reabsorptive $t_{\frac{1}{2}}$.

Fractional reabsorption at the end of the proximal convolution was estimated from the transit time, and reabsorptive $t_{1}$ from the expression given in the footnote to Table I. It is apparent that there was an immediate and progressive increase in fractional reabsorption from $49 \%$ in the control periods to $85 \%$ when aortic constriction had reduced femoral arterial BP to 70 to $75 \mathrm{~mm} \mathrm{Hg}$.

B) Complete fluid replacement (Group II, Table I). The first difference apparent in this group was that the kidneys were larger and the tubules more dilated. Stepwise reductions in blood pressure produced slight but definite reductions in kidney size. The marked contraction and blanching of the kidney that appeared below $80 \mathrm{~mm} \mathrm{Hg}$ in the animals in group 1 did not occur until the blood pressure was lowered below $50 \mathrm{~mm} \mathrm{Hg}$; in one animal these changes were not observed until the blood pressure was reduced to $30 \mathrm{~mm} \mathrm{Hg}$.

Reductions in BP to 60 to $65 \mathrm{~mm} \mathrm{Hg}$ lowered GFR by an average of $48 \%$ in contrast to the results in group 1 , where GFR was not measurable at BP below $80 \mathrm{~mm} \mathrm{Hg}$.

The mean transit time was remarkably constant and remained unchanged as $\mathrm{BP}$ was reduced to 60 to $65 \mathrm{~mm} \mathrm{Hg}$ (Table I) ; only at pressures below $50 \mathrm{~mm} \mathrm{Hg}$ (which are not charted) was the transit time prolonged. At pressures above 60 $\mathrm{mm} \mathrm{Hg}$ the dye appeared and disappeared from all the tubules more or less simultaneously. In this group, therefore, nephron function appeared to be relatively homogenous despite marked reductions in perfusion pressure.

There was no measurable change in the reabsorptive $t_{\frac{1}{2}}$ as blood pressure was reduced to 60 to $65 \mathrm{~mm} \mathrm{Hg}$ (Table I). Fractional reabsorption in the proximal tubule remained constant at a value of about $45 \%$ despite a reduction in $\mathrm{BP}$ to 60 to $65 \mathrm{~mm} \mathrm{Hg}$, a level that resulted in virtually complete reabsorption of filtrate in animals without fluid replacement.

Studies with increased ureteropelvic pressure. Measurements were made during elevation of ureteral pressure to ascertain the relation between tubular radius and reabsorptive $t_{\underline{t}}$ (Table II). 
TABLE JII

Representative experiment demonstrating effect of elevated ureteral pressure on proximal reabsorption

\begin{tabular}{cccc}
\hline $\begin{array}{c}\text { Ureteral } \\
\text { pressure }\end{array}$ & $\begin{array}{c}\text { Number } \\
\text { of meas- } \\
\text { urements }\end{array}$ & $\begin{array}{c}\text { Tubular } \\
\text { radius }\end{array}$ & $\begin{array}{c}\text { Reabsorptive } \\
\text { ts }\end{array}$ \\
\hline$m m$ Hg & & $\mu$ & seconds \\
0 & 3 & 15.0 & 9.0 \\
25 & 4 & 17.4 & 8.8 \\
40 & 9 & 19.4 & 9.3 \\
0 & 3 & 15.0 & 10.5 \\
\hline
\end{tabular}

Raising the hydrostatic pressure in the renal pelvis resulted in grossly visible swelling of the kidneys. Urine flow decreased when intrapelvic pressure was raised to 25 and $40 \mathrm{~mm} \mathrm{Hg}$, and upon further elevation to $60 \mathrm{~mm} \mathrm{Hg}$ there was flow of ureteral urine back into the renal pelvis.

The luminal radii were measured before the application (24 measurements) and after the release (23 measurements) of pelvic pressure to determine whether the period of hydronephrosis resulted in permanent changes in tubular size. There was no significant difference in the two measurements. The mean tubular radius for the combined measurements was $16.4 \pm 1.2 \mu$ (Table II). Stepwise increase in hydrostatic pressure resulted in a rise in tubular radius to $19.8 \pm 0.8 \mu$ at $40 \mathrm{~mm} \mathrm{Hg}$ intrapelvic pressure. At $60 \mathrm{~mm} \mathrm{Hg}$ intrapelvic pressure no further dilatation occurred, probably because the intrapelvic pressure was no longer transmitted to the proximal tubules $(7)$.

The control mean $t_{1}$ was $10.0 \pm 1.4$ seconds (Table II). The mean $t_{1}$ did not change significantly when the intrapelvic pressure was raised to 25 and $40 \mathrm{~mm} \mathrm{Hg}$, with mean values of $9.1 \pm$ 0.6 seconds ( 8 measurements) and $10.4 \pm 1.6 \mathrm{sec}-$ onds (28 measurements), respectively. At $60 \mathrm{~mm}$ $\mathrm{Hg}$ intrapelvic pressure, mean reabsorptive half-

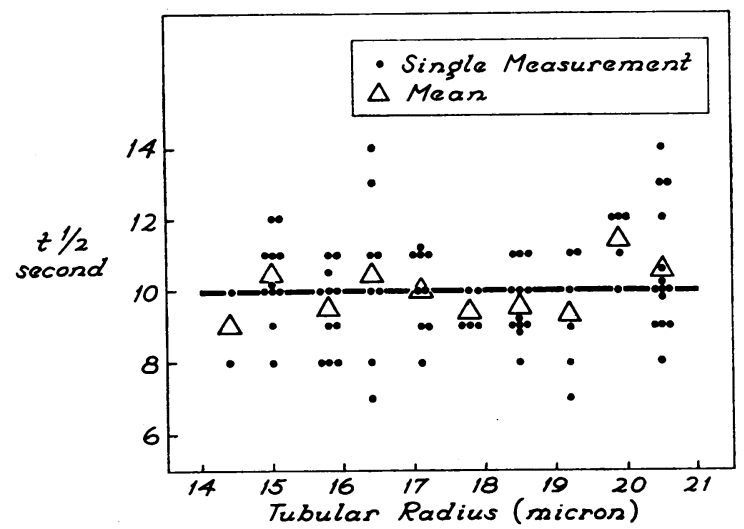

- Fig. 2. Relation between reabsorptive half-time (T⿱亠䒑 $)$ AND TUBULAR RADIUS DURING INCREASED URETERAL PRESSURE. The values are taken from Table II ; only data from experiments where ureteral pressure was 0,25 , or $40 \mathrm{~mm} \mathrm{Hg}$ are plotted.

time was increased to $14.6 \pm 3.0$ seconds. A typical experiment is shown in Table III.

The relation of tubular radius and $t_{1}$ when ureteral pressure was raised up to $40 \mathrm{~mm} \mathrm{Hg}$ is depicted in Figure 2. This Figure includes all the data listed in Table II, excluding only those points obtained at $60 \mathrm{~mm} \mathrm{Hg}$. It is apparent that the mean $t_{1}$ is constant despite wide variations in tubular radii from 14.4 to $20.5 \mu$.

Studies with combined aortic constriction and increased ureteral pressure. To further exclude the possibility that some hormonal or metabolic factor was inhibiting tubular reabsorption during aortic constriction and stimulating reabsorption during ureteral obstruction, we performed two experiments in which increased ureteral pressure was superimposed on aortic constriction. One of these experiments is illustrated in Table IV. During the control period the tubular radius was $15.2 \mu$, the $t_{2}$ was 10.2 seconds, and the reabsorptive rate constant was $0.492 \mathrm{~m} \mu \mathrm{l}$ per $\mathrm{cm}$ per sec-

TABLE IN

Effects of combined aortic constriction and elevated ureteral pressure on proximal reabsorption

\begin{tabular}{|c|c|c|c|c|}
\hline Procedure & $\begin{array}{c}\text { Number of } \\
\text { measurements }\end{array}$ & $\begin{array}{l}\text { Tubular } \\
\text { radius }\end{array}$ & $\underset{t}{\text { Reabsorptive }}$ & $\begin{array}{l}\text { Reabsorptive } \\
\text { rate constant }\end{array}$ \\
\hline & & $\mu$ & seconds & $m \mu l / c m / s e c o n d$ \\
\hline Control & 4 & 15.2 & 10.2 & 0.492 \\
\hline Aortic constriction & 4 & 13.5 & 10.5 & 0.378 \\
\hline $\begin{array}{l}\text { Aortic constriction }+ \\
\text { ureteral pressure }(25 \mathrm{~mm} \mathrm{Hg})\end{array}$ & 4 & 17.5 & 10.0 & 0.667 \\
\hline Ureteral pressure $(25 \mathrm{~mm} \mathrm{Hg})$ & 4 & 18.0 & 10.2 & 0.690 \\
\hline Control & 4 & 15.0 & 10.5 & 0.467 \\
\hline
\end{tabular}


ond. Lowering femoral arterial blood pressure to 70 to $75 \mathrm{~mm} \mathrm{Hg}$ by constricting the aorta above the renal arteries reduced the tubular radius to $13.5 \mu$, but did not change the $t_{\frac{1}{2}}$; consequently, the reabsorptive rate decreased to $0.378 \mathrm{~m} \mu \mathrm{l}$ per $\mathrm{cm}$ per second. The femoral blood pressure was then maintained at 70 to $75 \mathrm{~mm} \mathrm{Hg}$ while ureteral pressure was elevated to $25 \mathrm{~mm} \mathrm{Hg}$. The tubular radius increased to $17.5 \mu$, the $t_{1}$ remained constant at 10 seconds, and the reabsorptive rate rose to $0.667 \mathrm{~m} \mu \mathrm{l}$ per $\mathrm{cm}$ per second. The aortic constriction was then released, permitting femoral arterial blood pressure to return to control values, while the ureteral pressure of $25 \mathrm{~mm} \mathrm{Hg}$ was maintained. There was virtually no change in tubular radius, $t_{\frac{1}{2}}$, or reabsorptive rate. Similar results were obtained in the second experiment.

Validity of measurements of reabsorptive $t_{1}$. Extrapolation of the reabsorptive rates measured by the shrinking-drop technique to normal intact nephrons requires that the results obtained by this method be in accord with reabsorptive rates estimated from measurements during free flow.

The reabsorptive rate $(\mathrm{C})$ during free flow can be estimated in the manner proposed by Gertz (4) from the tubular fluid to plasma ratio of inulin, $(\mathrm{TF} / \mathrm{P})_{\mathrm{In}}$, transit time $(\mathrm{T})$, and tubular radius $(r)$, according to the following equation:

$$
\log (\mathrm{TF} / \mathrm{P})_{\mathrm{In}}=\frac{\mathrm{CT}}{2.3 \pi \mathrm{r}^{2}} .
$$

The validity of this equation was confirmed in our previous study by demonstrating that $\log (\mathrm{TF} /$ $P)_{\text {In }}$ was a linear function of transit time $(T)$. If the results from the shrinking-drop method can be validly extrapolated to free flow, the magnitude of the reabsorptive rate constant (C) in Equation 1 should be the same as the reabsorptive rate constant estimated from the shrinking-drop technique by the expression,

$$
\mathrm{C}=\frac{0.693 \pi \mathrm{r}^{2}}{\mathrm{t}_{\frac{1}{2}}}
$$

If we rearrange,

$$
\frac{C}{\pi r^{2}}=\frac{0.693}{t_{\frac{1}{2}}} .
$$

Since $t_{1}$ was constant over a wide range of tubular radii (Figure 3 ), the expression $\mathrm{C} / \pi \mathrm{r}^{2}$ must also have been constant. Therefore, Equation 3 can be

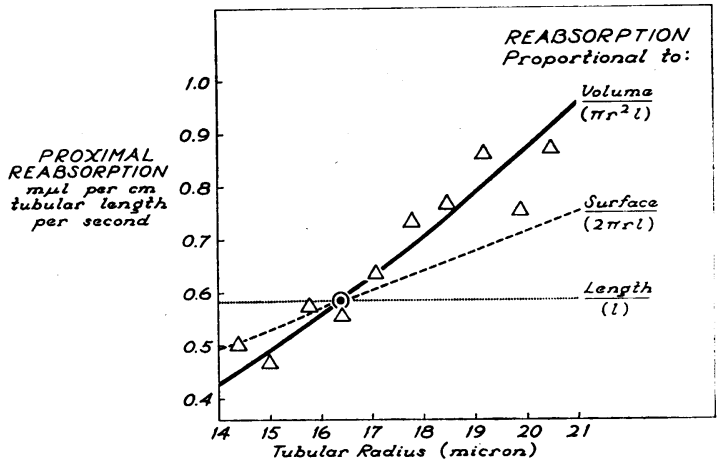

Fig. 3. RElation BetWeEN PROXIMAL REABSORPTIVE RATE AND TUBULAR RADIUS DURING INCREASED URETERAL PRESSURE. The open triangles are calculated from the mean reabsorptive half-times in Figure 2. The theoretical lines describe the predicted change in reabsorptive rate of an average proximal tubule, with a control reabsorptive rate of $0.59 \mathrm{~m} \mu \mathrm{l}$ per $\mathrm{cm}$ per second and a tubular radius of $16.5 \mu$, if reabsorption were a function of length, surface area, or volume. If reabsorptive rate per unit tubular length were uninfluenced by dilatation, the dotted line would describe the relationship between radius and reabsorption; if reabsorption increased in proportion to surface area, the dashed line, which is estimated from the equation $0.59 \mathrm{r} / 16.5$, would describe the relation. Finally, if reabsorption increased in proportion to tubular volume, the solid line, which is constructed from the expression $0.59 \mathrm{r}^{2} /(16.5)^{2}$, would describe the relation. $\mathrm{r}=$ tubular radius ; $1=$ length.

substituted into Equation 1 to give:

$$
\log (\mathrm{TF} / \mathrm{P})_{\mathrm{In}}=\frac{0.301 \mathrm{~T}}{\mathrm{t}_{\frac{1}{2}}} \text {. }
$$

This equation permits a comparison of fractional reabsorption, as estimated during free flow from the $(\mathrm{TF} / \mathrm{P})_{\text {In, }}$, with fractional reabsorption during shrinking-drop studies, as estimated from $t_{1}$ and $T$.

Since in the present experiments the average $\mathrm{T}$ was 9.6 seconds and the $t_{1}$ was 10.2 seconds, the predicted $(\mathrm{TF} / \mathrm{P})_{\text {In }}$ at the end of the accessible portion of the proximal tubule would be 1.92 . This compares extremely well with the $(\mathrm{TF} / \mathrm{P})_{\text {In }}$ values of approximately 2 obtained in the preceding study (3). In addition, plotting $(\mathrm{TF} / \mathrm{P})_{\text {In }}$ against $\mathrm{T}$ in the previous study (Figure 3 of reference 3 ) intercepted a $(\mathrm{TF} / \mathrm{P})_{\text {In }}$ of 2 at $8.5 \mathrm{sec}-$ onds, indicating that the reabsorptive $t_{1}$ during free flow was 8.5 seconds. Thus, there is excellent agreement between the reabsorptive rates measured directly with the shrinking-drop tech- 
nique and estimated indirectly from the $(\mathrm{TF} / \mathrm{P})_{\mathrm{In}}$ values during free flow.

\section{Discussion}

The maintenance of constant fractional reabsorption in the proximal tubule in the face of wide variations in GFR induced by aortic constriction (1-3) establishes that proximal reabsorption changes parallel with GFR. In the present studies the intrinsic reabsorptive capacity of the proximal tubular epithelium, measured directly with the shrinking-drop technique, was also related to GFR when the aorta was constricted above the renal arteries. In group $I$ the reabsorptive rate fell from 0.565 to $0.239 \mathrm{~m} \mu \mathrm{l}$ per $\mathrm{cm}$ per second as the perfusion pressure was lowered from 120 to $60 \mathrm{~mm} \mathrm{Hg}$; in group II reabsorptive rate declined from 0.606 to $0.416 \mathrm{~m} \mu \mathrm{l}$ per $\mathrm{cm}$ per second (Table I).

Although the decline in reabsorptive rate could be the consequence of some metabolic or humoral factor elaborated as a result of renal hypoperfusion, it is reasonable to examine whether the decrease in tubular size actually observed might be the regulatory factor. In fact, Gertz $(4,8)$ had suggested in previous studies that proximal reabsorption is in some way related to tubular size. In his initial studies (4) he found that the reabsorptive rate, measured directly in individual proximal tubules with the shrinking-drop technique, appeared to be proportionate to small spontaneous variations in tubular radius; in later studies (8) he found a better correlation with the square of the tubular radius. Because of the small range in the spontaneous variation in tubular size and the technical difficulty in accurately measuring tubular radius, it is difficult to establish the precise relation between reabsorptive rate and tubular size from Gertz's studies.

The present studies, in which the proximal tubules were dilated by applying pressure to the renal pelvis, permit a more critical assessment of the role of tubular geometry for two reasons. First, any changes in reabsorptive rate can be dissociated from the effects of renal hypoperfusion and attributed to alterations in tubular size. Second, the wider range in tubular size permits a more precise analysis of the relationship between reabsorptive rate and tubular radius.

It is apparent from Figure 2 that, despite the variation in tubular radii from 14.4 to $20.5 \mu$, the mean $t_{i}$ was constant over the whole range. Since $t_{1}$ is related to the reabsorptive rate (C) by the expression (4), $C / \pi r^{2}=0.693 / t_{k}$, the constancy of $t_{\frac{1}{2}}$ establishes that $C / \pi r^{2}$ is also constant. Therefore, the reabsorptive rate $(\mathrm{C})$ must vary proportionately to changes in tubular volume per unit length $\left(\pi r^{2}\right)$. A similar conclusion follows from the constancy of the reabsorptive $t_{\frac{1}{2}}$ during aortic constriction (Table I, first three periods of group I ; group II).

To examine whether reabsorption is a function of some geometrical parameter other than volume, we plotted the absolute rate of reabsorption as a function of radius (Figure 3 ). The open triangles represent the mean reabsorptive rates derived from shrinking-drop measurements from tubules of different radii (Figure 2). Three theoretical lines have been calculated and plotted. The dotted horizontal line represents the theoretical relation between tubular radius and reabsorptive rate if reabsorption were constant per unit tubular length. The dashed line represents the predicted relation if reabsorption were changing proportionately with tubular surface area. The solid line represents the relationship that would be expected if tubular reabsorption were changing proportionately to tubular volume. It is clear that our experimental values fall along the solid line. indicating that reabsorption is proportionate to tubular volume per unit length $\left(\pi r^{2}\right)$.

The present studies, therefore, indicate that the ratio of the reabsorptive rate to tubular volume $\left(\mathrm{C} / \pi \mathbf{r}^{2}\right)$ remains constant during both tubular shrinkage (aortic constriction) and tubular dilatation (increased ureteral pressure). A similar conclusion was reached on the basis of studies during free flow in our previous paper (3), where inferential arguments were advanced to suggest that tubular volume is not merely correlated with. but causally determines, reabsorption. The present studies furnish direct evidence in support of this hypothesis. The shrinking-drop technique. by examining the intrinsic reabsorptive characteristics of the renal tubule in isolation, excludes the possibility that the observed changes in reabsorptive rate were mediated by either velocity flow or some factor present in glomerular filtrate. The experiments that combine aortic constriction and ureteral pressure are particularly critical in ex- 
cluding metabolic or hormonal factors as regulatory influences. These studies disclosed (Table IV) that reabsorption was a function of tubular diameter irrespective of whether the setting was ischemia (aortic constriction), hydronephrosis (increased ureteral pressure), or both. Finally, although ureteral pressure is known to increase (9), and aortic constriction to decrease, cortical blood flow, alterations in renal blood flow cannot mediate this relationship since, with the same tubular volume, reabsorption remained constant during increased ureteral pressure either alone or with aortic constriction (Table IV). The shrinking-drop studies, therefore, have the advantage of disclosing the intrinsic characteristics of the tubular epithelium, and they furnish strong evidence that tubular volume is the causal factor regulating tubular reabsorption during both aortic constriction and increased ureteral pressure.

The finding that tubular reabsorption varies proportionately with changes in tubular volume is difficult to explain in the framework of the current model of proximal tubular reabsorption of $\mathrm{NaCl}$ and water (10). According to this model, $\mathrm{Na}^{+}$ diffuses passively into the tubular cell and is actively transported out of the cell at the peritubular border. The reabsorption of $\mathrm{Cl}^{-}$is thought to occur passively down the electrochemical gradient. The osmotic force created by the reabsorption of $\mathrm{Na}^{+}$and $\mathrm{Cl}^{-}$is considered to be responsible for the passive reabsorption of water. Changes in the rate of tubular reabsorption, therefore, could be due to increased activity of the $\mathrm{Na}^{+}$pump at the peritubular border, or decreased resistance to the passive movement of $\mathrm{Na}^{+}, \mathrm{Cl}^{-}$, and $\mathrm{H}_{2} \mathrm{O}$. It should be stressed that the increased reabsorption with tubular dilatation cannot be due to hydrostatic pressure gradients. Gottschalk and Mylle (7) have shown that, although intratubular pressure rises with applied ureteral pressure, there is no pressure gradient from the tubular lumen to the peritubular capillary.

It is unlikely that simple stretching of the tubular wall would increase either the number or the activity of active transport sites. It is much more likely that the luminal membrane would be altered and the passive movement of $\mathrm{Na}^{+}, \mathrm{Cl}^{-}$, and $\mathrm{H}_{2} \mathrm{O}$ into the cell facilitated. Although surface area for passive diffusion might increase as a simple function of radius, this would not meet the observed requirement that reabsorption increased proportionately, not to the radius, but rather to the square of the radius. However, if the ratelimiting step in tubular reabsorption were not the diffusion of $\mathrm{Na}^{+}$, but rather the bulk flow of fluid through pores in the luminal membrane, dilatation could have the effect of increasing pore size. The cross-sectional area of pores in the luminal membrane is a function of two dimensions; one dimension $\left(d_{1}\right)$ is oriented in the direction of the tubular circumference $(2 \pi \mathrm{r})$, whereas the other $\left(d_{2}\right)$ is in the direction of tubular length. According to Poiseuille's law, bulk flow through such pores is a function of $\mathrm{d}_{1}{ }^{2} \times \mathrm{d}_{2}{ }^{2}$. Although it is recognized that bulk flow of water through pores the size of those present in most biologic membranes ( 4 to $6 \mathrm{~A}$ ) does not behave according to Poiseuille's law (11), the size of the pores in the luminal membrane of the proximal tubular epithelium is not known and, in fact, may be much larger than those in other membranes. Preliminary studies in our laboratory indicate that the equivalent pore radius in the proximal convoluted tubule is between 15 and $25 \mathrm{~A}$. If this proves to be the correct size of the channels through which the tubular solution is flowing, then the flow should follow Poiseuille's law reasonably closely and exhibit dependence on the square of each of the dimensions of the pore $\left(\mathrm{d}_{1}{ }^{2}\right.$ and $\left.\mathrm{d}_{2}{ }^{2}\right)$. Since, during distension with fluid, the tubule does not appreciably elongate, ${ }^{2}$ but rather dilates in its cross-sectional dimension, $\mathrm{d}_{2}$ might remain constant and $d_{1}$ might increase in direct proportion to tubular radius. Bulk flow could therefore increase as does the square of the tubular radius. As bulk flow of tubular fluid into the cell increased, the cytoplasmic concentration of $\mathrm{Na}^{+}$would be expected to rise proportionately, thereby stimulating the active outward transport of $\mathrm{Na}^{+}$.

These results should not be taken to mean that tubular reabsorption changes proportionately to tubular volume under all circumstances. As indicated in Table I, the relation between reabsorptive rate and tubular volume was disrupted in group I rats when the renal perfusion pressure was lowered to the extent that the kidney appeared

\footnotetext{
${ }^{2}$ Any effects resulting from elongation of the pores in the longitudinal direction of the tubule would be partially cancelled in the shrinking-drop measurements by a decrease in the number of pores per unit of measured length.
} 
very pale, glomerular filtration practically ceased (as concluded from the very prolonged transit time of Lissamine green along the proximal convolution), and urine formation stopped. Under these circumstances reabsorptive rate decreased disproportionately to tubular volume and $t_{\frac{1}{2}}$ increased. This change, however, occurred only after the GFR was depressed below the range of glomerulotubular balance, as indicated by the rise in calculated fractional reabsorption (Table I). Although it is conceivable that these changes were the consequence of excessive release of renin and angiotensin (12), an equally possible explanation is that marked reductions of peritubular blood flow inhibited proximal reabsorption by limiting the rate at which reabsorbate could be removed from the peritubular space.

\section{Summary}

The relation of tubular reabsorption to tubular dimensions in the proximal convolution of the rat was examined during aortic constriction and during elevated ureteral pressure. Reabsorptive rate was estimated directly from the time (reabsorptive half-time) required to reabsorb $50 \%$ of a drop of saline instilled into the proximal tubule between two oil droplets. The shrinking-drop technique permits the examination of reabsorption independent of glomerular filtration, velocity flow, and hormonal influences.

Proximal tubular volume decreased with constriction of the aorta and increased with elevation of ureteral pressure. It was demonstrated in both experimental procedures that the reabsorptive half-time remained remarkably constant over a wide range of tubular radii. We concluded, therefore, that during aortic constriction and elevated ureteral pressure, either alone or in combination, proximal reabsorption changes in direct proportion to tubular volume.

\section{References}

1. Dirks, J. .H., W. J. Cirksena, and R. W. Berliner. The effect of saline infusion on sodium reabsorption by the proximal tubule of the dog. J. clin. Invest. $1965,44,1160$.

2. Glabman, S., H. S. Aynedjian, and N. Bank. Micropuncture study of the effect of acute reductions in glomerular filtration rate on sodium and water reabsorption by the proximal tubules of the rat. J. clin. Invest. 1965, 44, 1410.

3. Rector, F. C., Jr., F. P. Brunner, and D. W. Seldin. Mechanism of glomerulotubular balance. I. Effect of aortic constriction and elevated ureteropelvic pressure on glomerular filtration rate, fractional reabsorption, transit time, and tubular size in the proximal tubule of the rat. J. clin. Invest. 1966, $45,590$.

4. Gertz, K. H. Transtubuläre Natriumchloridflüsse und Permeabilität für Nichtelektrolyte im proximalen und distalen Konovolut der Rattenniere. Pflügers Arch. ges. Physiol. 1963, 276, 336.

5. Steinhausen, M. Eine Methode zur Differenzierung proximaler und distaler Tubuli der Nierenrinde von Ratten in vivo und ihre Anwendung zur Bestimmung tubulärer Strömungsgeschwindigkeiten. Pflügers Arch. ges. Physiol. 1963, 277, 23.

6. Giebisch, G., R. M. Klose, G. Malnic, W. J. Sullivan, and E. E. Windhager. Sodium movement across single perfused proximal tubules of rat kidneys. J. gen. Physiol. 1964, 47, 1175.

7. Gottschalk, C. W., and M. Mylle. Micropuncture study of pressure in proximal tubules and peritubular capillaries of the rat kidney and their relation to ureteral and renal venous pressures. Amer. J. Physiol. 1956, 185, 430.

8. Gertz, K. H. Personal communication.

9. Thurau, K. Renal hemodynamics. Amer. J. Med. 1964, 36, 698.

10. Giebisch, G. Measurements of electrical potential differences on single nephrons of the perfused Necturus kidney. J. gen. Physiol. 1961, 44, 659.

11. Renkin, E. M. Filtration, diffusion, and molecular sieving through porous cellulose membranes. J. gen. Physiol. 1954, 38, 225.

12. Gertz, K. H. Direct measurement of the transtubular flux of electrolytes and nonelectrolytes in the intact rat kidney in Proceedings of the 22nd International Congress on Physiological Sciences, Leiden, Excerpta Medica Foundation, 1962, p. 370. 